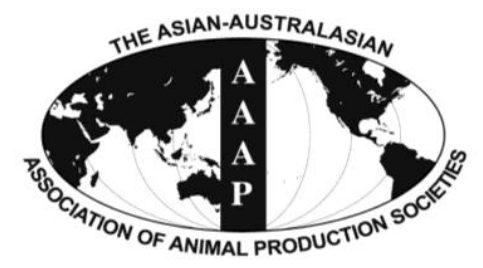

Asian-Aust. J. Anim. Sci.

Vol. 25, No. 6 : 794 - 799

June 2012

www.ajas.info

http://dx.doi.org/10.5713/ajas.2011.11489

\title{
Polymorphysims of CYP17-IGene in the Exons Were Associated with the Reproductive Endocrine of Japanese Flounder (Paralichthys olivaceus)
}

\author{
R. Q. Ma, F. He*, H. S. Wen, J. F. Li, W. J. Mu, M. Liu, Y. Q. Zhang, J. Hu and L. Qun \\ Fisheries College, Ocean University of China, Qingdao 266003, China
}

\begin{abstract}
The cytochrome P450c17-I (CYP17-I) is one of the enzymes critical to gonadal development and the synthesis of androgens. Two single nucleotide polymorphisms (SNPs) were detected within the coding region of the CYP17-I gene in a population of 75 male Japanese flounder (Paralichthys olivaceus). They were SNP1 (c.C445T) located in exon2 and SNP2 (c.T980C (p.Phe307Leu)) located in exon5. Four physiological indices, which were serum testosterone (T), serum 17 $\beta$-estradiol $\left(\mathrm{E}_{2}\right)$, Hepatosomatic index (HSI), and Gonadosomatic index (GSI), were studied to examine the effect of the two SNPs on the reproductive endocrines of Japanese flounder. Multiple comparisons revealed that CT genotype of SNP1 had a much lower T level than CC genotype $(\mathrm{p}<0.05)$ and the GSI of individuals with CC genotype of SNP2 was higher than those with TT genotype ( $<<0.05)$. Four diplotypes were constructed based on the two SNPs and the diplotype D3 had a significantly lower T level and GSI. In conclusion, the two SNPs were significantly associated with reproductive traits of Japanese flounder. (Key Words: CYP17-I Gene, SNPs, SSCP, Japanese Flounder)
\end{abstract}

\section{INTRODUCTION}

Single nucleotide polymorphism (SNP) is single base pair positions in genomic DNA at which different sequence alternatives (alleles) exist in normal individuals. But the least frequent allele has an abundance of $1 \%$ or greater (Brookes, 1999). SNPs are very abundant across most genomes and occur approximately one in every $225 \mathrm{bp}$ in chickens and one in every 1,250 bp in humans (Liu, 2007). With the development of DNA-based marker assays and high throughput genotyping technologies, SNPs have become markers of choice for large scale mapping and genotyping (Rafalski, 2002; Liu and Cordes, 2004). SNP analysis has been widely used in human disease genetics, pharmacogenetics, and animal breeding (Liao and Lee, 2010). Furthermore, SNP markers have also been used to screen functional genes in a number of aquatic species, including Japanese flounder (He et al., 2011), rainbow trout (Cecilia et al., 2009), goldfish (Chang et al., 2009), giant freshwater prawn (Thanh et al., 2010), giant tiger shrimp (Sirikan et al., 2010), common carp (Pawapol et al., 2010) and gilthead seabream (Carmen et al., 2011). Single-strand conformation polymorphism (SSCP) is useful as a

\footnotetext{
* Corresponding Author: F. He. Tel: +86-532-82031953, E-mail: hefengouc@ouc.edu.cn

Submitted Dec. 16, 2011; Accepted Jan. 17, 2012; Revised Feb. 3, 2012
}

diagnostic tool for examining genetic diversity due to SNPs in various species owing to its convenience and cost effectiveness (Orita et al., 1989).

Cytochrome P450c17 (17 $\alpha$-hydroxylase/C17-20 lyase, CYP17) is essential for the production of $17 \alpha$-hydroxylated progestins in gonadal tissues and cortisol in adrenal tissues (Kazeto et al., 2000). Fish have two types of p450c17s, P450c17-I and P450c17-II. They are encoded by CYP17-I and CYP17-II genes, respectively. CYP17-I gene encodes an enzyme with both 17 $\alpha$-hydroxylase and 17, 20-lyase activities. $17 \alpha$-hydroxylase is responsible for hydroxylating pregnenolone and progesterone to their $17 \alpha-\mathrm{OH}$ derivatives, and then converted by 17,20 -lyase to dehydroepiandrosterone and androstenedione and subsequently to testosterone and estrogens (Nakajin et al., 1981; Payne, 1990; Conley and Bird, 1997). The polymorphisms of the CYP17 gene were extensively studied using SNPs in both human beings and animals.

However, there has been no report about SNPs of CYP17-I gene in fish until now. The purpose of this study was to investigate the SNPs of Japanese flounder CYP17-I gene which had been obtained (Genbank ID: FJ815204) and then analyze the effects of these SNPs on the reproductive endocrines. Four physiological indices were used to measure these effects. They were serum testosterone (T), serum $17 \beta$-estradiol $\left(\mathrm{E}_{2}\right)$, Hepatosomatic index (HSI) and 
Gonadosomatic index (GSI).

\section{MATERIALS AND METHODS}

\section{Experimental fish}

All the experimental fish (six months) used in the present experiment were provided by the Shandong Kehe High Technology Co., Ltd. Fish were reared in natural sea water under the controlled conditions $\left(20 \pm 0.5^{\circ} \mathrm{C}\right.$; $\geq 4 \mathrm{mg} / \mathrm{L} \mathrm{O}_{2} ; 14: 10 \mathrm{~h}$ light:dark cycle). One hundred male Japanese flounder were sampled randomly and then anesthetized before the experiment. Blood was extracted from the fish tail with disposable syringes, and then stored at $4{ }^{\circ} \mathrm{C}$. During the sampling process, four measurements were recorded including their wet weights, body lengths and the weights of gonad and liver. Muscle samples were separated and then stored at $-80^{\circ} \mathrm{C}$.

Primer design, DNA extraction and polymerase chain reaction (PCR)

Primers were designed using Oligo 6.0 software. Seven primer sets were designed for the CYP17-I gene of Japanese flounder based on the 8 exons (Table 1). The primers of exon 4 were not designed because its sequence was less than 100 base pairs (bp).

Total DNA was extracted from the frozen muscle samples using the phenolchloroform method. The DNA purity and concentration were measured using an UV spectrotometer (Amersham, American). There were 75 samples suitable for use in the SSCP analysis.

The PCR reaction was performed in a volume of $25 \mu \mathrm{l}$ containing of $2.5 \mu \mathrm{l}$ of $10 \times \mathrm{PCR}$ Buffer, $80 \mathrm{ng}$ of genomic DNA, $0.20 \mathrm{mM}$ each dNTP, $0.50 \mathrm{mM}$ each primer and 0.25 U Taq DNA polymerase (rTaq TaKaRa). The cycling conditions were carried out with an initial denaturation step for $5 \mathrm{~min}$ at $94^{\circ} \mathrm{C}$, followed by 35 cycles consisting of three steps: $94^{\circ} \mathrm{C}$ for $30 \mathrm{~s}, 59$ to $63^{\circ} \mathrm{C}$ for $30 \mathrm{~s}, 72^{\circ} \mathrm{C}$ for $30 \mathrm{~s}$. A final extension was performed at $72^{\circ} \mathrm{C}$ for $10 \mathrm{~min}$.

\section{Single-stranded conformation polymorphism (SSCP)} analysis and sequencing

The amplification product was analyzed by SSCP (He et al., 2008). Five $\mu$ l PCR products from each individual were mixed with $8 \mu$ l denaturing buffer (98\% formamide, $0.09 \%$ xylene cyanole FF, and $0.09 \%$ bromophenol blue). Each mixture was heat-denatured at $98^{\circ} \mathrm{C}$ for $10 \mathrm{~min}$ and then immediately chilled on ice for $10 \mathrm{~min}$. The denatured products of $C Y P 17-I$ gene were electrophoretically analyzed (10\% PAGE; 29:1 crosslink) at $120 \mathrm{~V}$ for 12 to $14 \mathrm{~h}$ at room temperature. SSCP patterns on the gels were visualized by silver staining (Qu et al., 2005). The location and chemical nature of each mutation was confirmed by sequencing of the re-amplified product.

\section{Hepatosomatic index (HSI) and Gonadosomatic index (GSI)}

The Hepatosomatic index or Gonadosomatic index of each animal was calculated as the following formula:

$$
\begin{aligned}
& \text { HSI }=(\text { liver weight } /(\text { body weight-viscera weight })) \times 100 \\
& \text { GSI }=(\text { gonad weight } /(\text { body weight-viscera weight })) \times 100
\end{aligned}
$$

\section{Steroid radioimmunoassay (RIA)}

Blood samples stored at $4^{\circ} \mathrm{C}$ for $8 \mathrm{~h}$ were centrifugated at $12,000 \mathrm{~g}$ for $10 \mathrm{~min}$. The serum was transferred into $1.5-$ $\mathrm{ml}$ plastic microfuge tubes and then stored at $-40^{\circ} \mathrm{C}$. The serum testosterone and estradiol-17 $\beta$ were quantified by ${ }^{125} \mathrm{I}$ radioimmunoassay, using diagnostic kits from Diagnostic Products Corporation (Tianjin Nine Tripods Medical \& Bioengineering Co., Ltd., Sino-US jointventure enterprise). The method was provided by Wen et al. (2006).

\begin{tabular}{|c|c|c|c|c|}
\hline Names & Sequences & Length (bp) & $\operatorname{Tm}\left({ }^{\circ} \mathrm{C}\right)$ & Amplications \\
\hline Primer 1 & $\begin{array}{l}\text { GCTCTTCTCTGTGATGCTTGGTC } \\
\text { TCTGGGTCTCCCTGCAAATGTC }\end{array}$ & 353 & 62 & Exon 1 \\
\hline Primer 2 & $\begin{array}{l}\text { CCACTGATGTTCTGACCAGAGATGG } \\
\text { CTTCTCAATGGATGCAGAGCCCT }\end{array}$ & 131 & 63 & Exon 2 \\
\hline Primer 3 & $\begin{array}{l}\text { TGCAGAGGCCCAGTCTTTGTG } \\
\text { CCACGGGAAGATGTCAACTAGGC }\end{array}$ & 226 & 63 & Exon 3 \\
\hline Primer 4 & $\begin{array}{l}\text { CCATGTGCAGAGAGACCTACTGG } \\
\text { GGAAGGTGACAGCCCATTTGAG }\end{array}$ & 188 & 63 & Exon 5 \\
\hline Primer 5 & $\begin{array}{l}\text { CAGAGACGTATCCAGGAGGAGCT } \\
\text { GTGTCACTGAGGGCCACATG }\end{array}$ & 164 & 62 & Exon 6 \\
\hline Primer 6 & $\begin{array}{l}\text { TTGGGGACTTCACTGTGAGG } \\
\text { AGGGTCAAAGAGCTCAGGGT }\end{array}$ & 101 & 59.5 & Exon 7 \\
\hline Primer 7 & $\begin{array}{l}\text { CGGTTCTTAAACAATGATGGCAC } \\
\text { TTGGGGAACAGTTAGTTGACACTG }\end{array}$ & 447 & 59 & Exon 8 \\
\hline
\end{tabular}

Table 1. Primer sequences and information of Japanese flounder CYP17-I gene 


\section{Statistical analysis}

The SNP genotype of an individual at each SNP site was determined based on SSCP patterns and sequencing chromatograms. The genotype frequencies and allele frequencies for each polymorphism were calculated by Microsoft Excel. ANOVA tests for associations of SNP genotypes with reproductive traits (T, $\mathrm{E}_{2}, \mathrm{HSI}$ and GSI) were performed using Stat View software version 9.0 (SAS Institute Inc., Cary, NC). Significant differences among means of different genotypes were calculated using Duncan's multiple-range test and $\mathrm{p}$ values no more than 0.05 were considered statistically significant.

\section{RESULTS}

\section{Polymorphisms within exons of CYP17-I gene}

The analysis of the 75 individuals by PCR-SSCP showed that primer2 and primer5 had two different migration patterns, respectively (Figure 1). After direct sequencing, we found two different alterations (Figure 2). One was a C445T transition localized at primer2 and we named it SNP1. It was a synonymous mutation which did not change the amino acid Histidine. Two genotypes were found for the SNP1 and named as CC and CT. The other alteration was a T980C transition located at primer5 and we named it SNP2. The SNP2 was a non-synonymous mutation leading to an amino acid change from $\mathrm{Phe}^{307}$ to $\mathrm{Leu}^{307}$. Two genotypes were found for the SNP2 and named as TT and CC.

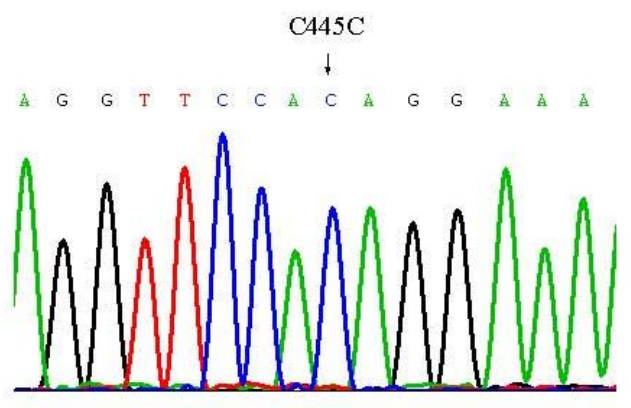

A

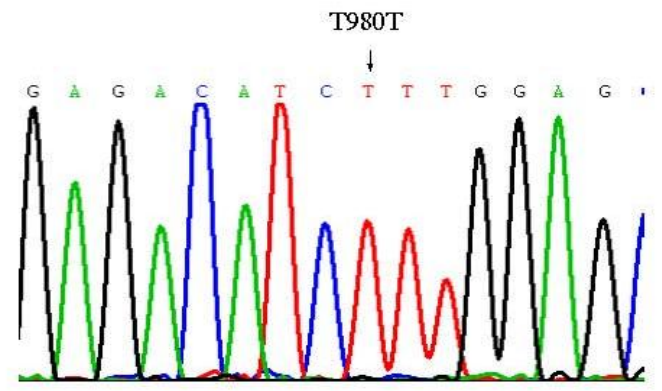

C

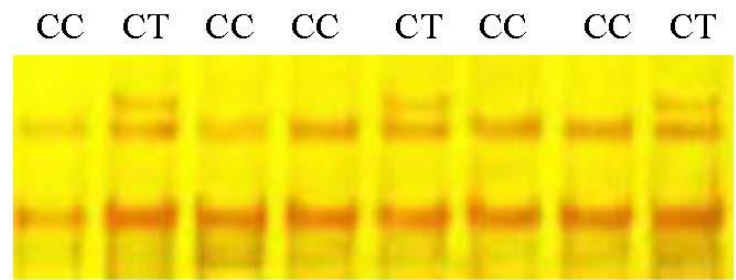

A

\section{$\begin{array}{llllllll}\mathrm{CC} & \mathrm{TT} & \mathrm{TT} & \mathrm{CC} & \mathrm{TT} & \mathrm{TT} & \mathrm{CC} & \mathrm{TT}\end{array}$}

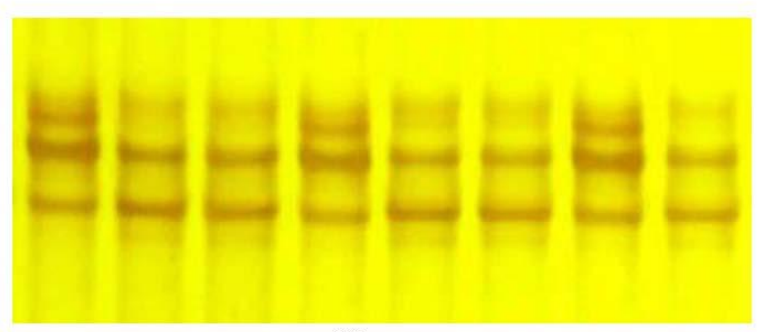

B

Figure 1. Band patterns for the two SNPs. (A) Genotypes of SNP1; (B) Genotypes of SNP2.

\section{Frequencies of genotypes and alleles}

The frequencies of genotypes and alleles of the two SNPs were showed in Table 2.

The CT genotype of SNP1 and the CC genotype of SNP2 were respectively $10.67 \%$ and $13.33 \%$ which were obviously lower than the other genotypes. In addition, the two SNPs were both bi-allelic, each SNP site varied

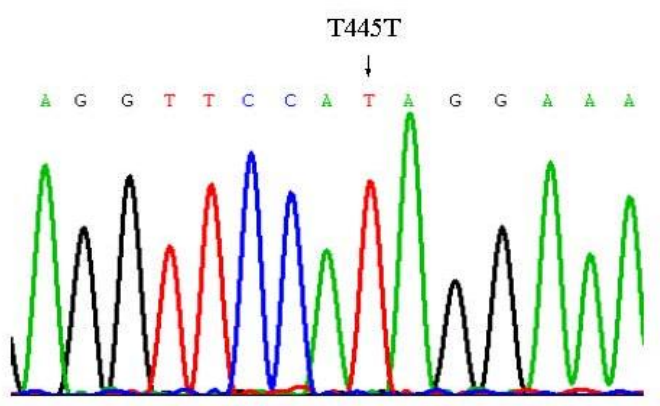

B

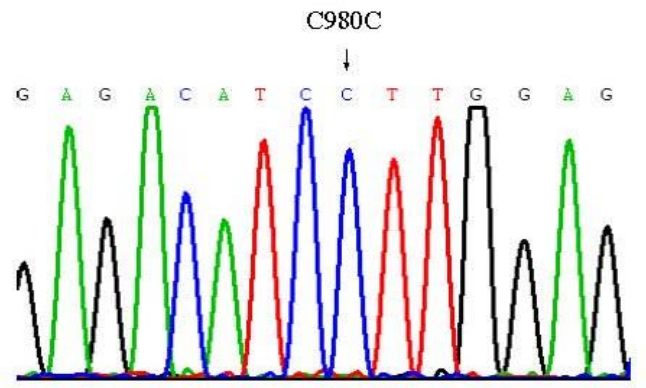

D

Figure 2. Sequences of the two SNPs. (A) Sequence of CC genotype of SNP1 locus; (B) Sequence of CT genotype of SNP1 locus; (C) Sequence of TT genotype of SNP2 locus; (D) Sequence of CC genotype of SNP2 locus. 
Table 2. Genotypes and alleles frequencies of two SNPs of Japanese flounder CYP17-I gene (\%)

\begin{tabular}{lcccccr}
\hline \multirow{2}{*}{ Locus } & \multicolumn{3}{c}{ Genotype frequency } & & \multicolumn{2}{c}{ Allele frequency } \\
\cline { 2 - 3 } \cline { 6 - 6 } & CC & CT & TT & & C & T \\
\hline SNP1 & 89.33 & 10.67 & - & & 94.67 & 5.33 \\
SNP2 & 13.33 & - & 86.67 & & 13.33 & 86.67 \\
\hline
\end{tabular}

between only two nucleotides.

\section{SNPs and reproductive traits association analysis}

GLM estimation was performed to analyze the associations of SNPs in CYP17-I gene with reproductive traits (Table 3). The results showed that SNP1 was significantly associated with $\mathrm{T}$ level $(\mathrm{p}<0.05)$ while SNP2 had significantly associations with GSI $(\mathrm{p}<0.05)$. Multiple comparisons (Table 4) revealed that the individuals with CT genotype had a much lower $\mathrm{T}$ level than those with $\mathrm{CC}$ genotype in SNP1 $(p<0.05)$. GSI of individuals with $C C$ genotype in SNP2 was higher than the TT genotype individuals $(\mathrm{p}<0.05)$.

\section{Construction of diplotypes and the correlation between} diplotypes and the reproductive traits

Four diplotypes were constructed and Table 5 shows the associations between diplotypes and the reproduction traits. The results indicated that there was a significant association between diplotypes and $\mathrm{T}$ level and GSI $(\mathrm{p}<0.05)$. The $\mathrm{T}$ level of diplotype D3 and D4 was lower than other diplotypes. What's more, the GSI of diplotypes D1 and D3 was lower than diplotypes D2 and D4. It is clear that D3 had both lower T level and GSI than other diplotypes.

\section{DISCUSSIONS}

Our study is the first to report the SNPs of CYP17-I gene in Japanese flounder. What we have established in this work were associations between SNPs of CYP17-I gene and the four reproduction traits $\left(\mathrm{T}, \mathrm{E}_{2}, \mathrm{GSI}, \mathrm{HSI}\right) . \mathrm{P} 450$ $17 \alpha$-hydroxylase, 17, 20-lyase (P450c17) encoded by CYP17-I gene is a key steroidogenic enzyme in the production of androgens. Androgens are essential for normal male sexual differentiation and development, and any abnormality in their production can have detrimental consequences for normal sexual development (Halm et al., 2003).

The most important result we found was that individuals with CT genotype of SNP1 had a much lower T level than those with CC genotype, although the SNP1 was a synonymous mutation. Many studies on both humans and animals have reported that a genetic polymorphism existing in the coding region or promoter region is expected to be associated with a small or moderate affect on the gene function (Weber and Nathanson, 2000). In human beings, many studies regarding single nucleotide polymorphisms of CYP17 gene have been reported. The mutation T34C located in the promoter of $C Y P 17$ gene could enhance its activity and then increase the bioavailability of testosterone and its metabolite dihydrotestosterone (Hamada et al.,

Table 3. Associations between each of the SNPs of Japanese flounder and reproductive traits

\begin{tabular}{|c|c|c|c|c|c|c|c|c|}
\hline \multirow{2}{*}{ Locus } & \multicolumn{2}{|c|}{$\mathrm{T}$ (ng/dl) } & \multicolumn{2}{|c|}{$\mathrm{E}_{2}(\mathrm{pg} / \mathrm{ml})$} & \multicolumn{2}{|c|}{ HSI $(\%)$} & \multicolumn{2}{|c|}{ GSI (\%) } \\
\hline & F value & $\mathrm{p}$ value & F value & $\mathrm{p}$ value & $\mathrm{F}$ value & $\mathrm{p}$ value & F value & $\mathrm{p}$ value \\
\hline SNP1 & 8.84 & $0.0040 *$ & 0.11 & 0.7450 & 0.12 & 0.7258 & 0.35 & 0.5579 \\
\hline SNP2 & 1.23 & 0.2701 & 0.89 & 0.3495 & 0.04 & 0.8373 & 6.84 & $0.0108^{*}$ \\
\hline
\end{tabular}

$* \mathrm{p} \leq 0.05$.

Table 4. Multiple comparisons of reproductive traits among different genotypes of two SNPs locus

\begin{tabular}{lcccc}
\hline Locus & Physiological index & CC genotype & CT genotype & TT genotype \\
\hline SNP1 & T (ng/dl) & $105.422 \pm 7.323^{\mathrm{a}}$ & $40.830 \pm 4.834^{\mathrm{b}}$ & - \\
SNP2 & GSI $(\%)$ & $0.8259 \pm 0.128^{\mathrm{a}}$ & - & $0.5385 \pm 0.041^{\mathrm{b}}$ \\
\hline
\end{tabular}

${ }^{1}$ Means \pm standard deviation.

${ }^{\mathrm{a}, \mathrm{b}}$ Different superscript letters of means within a same column indicate significant differences at $\mathrm{p}<0.05$.

Table 5. Diplotypes frequencies of CYP17-I gene and associations with reproductive traits in Japanese flounder

\begin{tabular}{lccccc}
\hline Diplotype & SNP1 & SNP2 & Frequency $(\%)$ & T (ng/dl) & GSI (\%) \\
\hline D1 & CC & TT & 81.33 & $105.862 \pm 7.599^{\mathrm{a}}$ & $0.555 \pm 0.041^{\mathrm{bc}}$ \\
D2 & CC & CC & 8.00 & $106.947 \pm 4.228^{\mathrm{a}}$ & $0.706 \pm 0.129^{\mathrm{ab}}$ \\
D3 & CT & TT & 5.33 & $44.822 \pm 3.673^{\mathrm{b}}$ & $0.280 \pm 0.158^{\mathrm{c}}$ \\
D4 & CT & CC & 5.33 & $36.838 \pm 3.730^{\mathrm{b}}$ & $1.006 \pm 0.158^{\mathrm{a}}$ \\
\hline
\end{tabular}

${ }^{1}$ Means \pm standard deviation. ${ }^{\mathrm{a}, \mathrm{b}, \mathrm{c}}$ Different superscript letters of means within a same column indicate significant differences at $\mathrm{p}<0.05$. 
2007). The T27C polymorphism in the 5' promoter region of CYP17 gene has been implicated as a risk factor for prostate cancer (Wei et al., 2010). The mutation T1931C enhanced the transcription of the CYP17 gene and has been shown to be associated with breast cancer risk (Miyoshi et al., 2003). Several synonymous mutations have been reported to alter gene expression or protein folding (Chamary et al., 2006; Sauna et al., 2007; Gupta and Lee, 2008; Liao and Lee, 2010). So we speculate that the presence of this polymorphism may limit the activity of P450c17 and then decrease androgen production. Further studies of this type are required, specifically to test for any association between the SNP1 of the CYP17-I gene and the activity of $\mathrm{P} 450 \mathrm{c} 17$.

A peculiar aspect of our results is the higher GSI level of the CC genotype compared to the TT genotype for the SNP2 $(p<0.05)$. In fish, the gonads are the main organs for the expression of $\mathrm{P} 450 \mathrm{c} 17 \mathrm{~s}$. GSI indicates a difference in the gonadal developmental status. It can be concluded that the gonads of individuals with TT genotype had not developed as well as in individuals with the CC genotype. The mutation T980C may affect the gonads development. However, our study found no differences in the levels of $\mathrm{T}$ and $E_{2}$ based on the SNP2 genotypes.

Following the recent research regarding diplotypes ( $\mathrm{He}$ et al., 2011), we constructed four diplotypes based on the two SNPs in this study. Among the four diplotypes, D3 was significantly associated with $\mathrm{T}$ level and GSI $(\mathrm{p}<0.05)$. What's more, D4 which was constructed by united SNP1 and SNP2 had a lower T level and higher GSI compared with D1. It provided further explanation that the two SNPs could lead to the deficiency of androgens and gonads dysplasia. So we speculate that D3 and D4 may be a promising molecular marker for marker assisted breeding.

In conclusion, two SNPs were detected and they were both associated with the reproductive endocrines of Japanese flounder. The SNP1 located in exon2 was significantly associated with serum $\mathrm{T}$ level $(\mathrm{p}<0.05)$. Individuals with CT genotype of SNP1 had a much lower T level than the CC genotype. The TT genotype of SNP2 located in exon5 had a lower GSI than the CC genotype $(p<0.05)$. To the best of our knowledge, this is the first report on the CYP17-I gene polymorphisms in the teleosts. SNPs identified in the present study have potential applications in breeding programs. Therefore, further studies are needed at the transcriptional regulation level and protein level for deeper insights into the SNPs effects on the physiological functions of P450c17-I. In general, SNPs have high potential for applications in aquaculture.

\section{ACKNOWLEDGEMENTS}

This work was supported by Natural Science Foundation of Shandong Province, China (No.
ZR2009DQ011), New Teacher Special Fund of Doctor of Ministry of Education of China (No. 20090132120006) and Postdoctoral Innovative Projects of Shandong Province, China (No.200702039).

\section{REFERENCES}

Brookes, A. J. 1999. The essence of SNPs. Gene 234:177-186.

Carmen, G. F., A. S. José and B. Gloria. 2011. Characterization of the gilthead seabream (Sparus aurata L.) transferrin gene: Genomic structure, constitutive expression and SNP variation. Fish Shellfish Immunol. 31:548-556.

Cecilia, C. S., P. L. Timothy, T. W. Ralph, L. V. Roger, S. Mohamed, Y. Jianbo and E. R. Caird. 2009. Single nucleotide polymorphism discovery in rainbow trout by deep sequencing of a reduced representation library. BMC Genomics 10:559.

Chamary, J. V., J. L. Parmley and L. D. Hurst. 2006. Hearing silence: non-neutral evolution at synonymous sites in mammals. Nat. Rev. Genet. 7:98-108.

Chang, J. P., J. D. Johnson, G. R. Sawisky, C. L. Grey, G. Mitchell, M. Booth, M. M. Volk, S. K. Parks, E. Thompson, G. G. Goss, C. Klausen and H. R. Habibi. 2009. Signal transduction in multifactorial neuroendocrine control of gonadotropin secretion and synthesis in teleosts-studies on the goldfish model. Gen. Comp. Endocrinol. 161:42-52.

Conley, A. J. and I. M. Bird. 1997. The role of cytochrome P450 $17 \alpha$-hydroxylase and $3 \beta$-hydroxysteroid dehydrogenase in the integration of gonadal and adrenal steroidogenesis via the $\Delta 5$ and $\Delta 4$ pathways of steroidogenesis in mammals. Biol. Reprod. 56:789-799.

Gupta, P. and K. H. Lee. 2008. Silent mutations result in HlyA hypersecretion by reducing intracellular HlyA protein aggregates. Biotechnol. Bioeng. 101:967-974.

Halm, S., J. Y. Kwon, M. Rand-Weaver, J. P. Sumpter, N. Pounds, T. H. Hutchinson and C. R. Tyler. 2003. Cloning and gene expression of P450 17 $\alpha$-hydroxylase, 17, 20-lyase cDNA in the gonads and brain of the fathead minnow Pimephales promelas. Gen. Comp. Endocrinol. 130:256-266.

Hamada, A., R. Danesi, D. K. Price, T. Sissung, C. Chau, D. Venzon, A. Sparreboom, W. L. Dahut and W. D. Figg. 2007. Association of a CYP17 polymorphism with overall survival in caucasian patients with androgen-independent prostate cancer. Urology 70:217-220.

He, F., H. S. Wen, S. L. Dong, L. S. Wang, C. F. Chen, B. Shi, X. J. $\mathrm{Mu}$, J. Yao and Y. G. Zhou. 2008. Identification of estrogen receptor $\alpha$ gene polymorphisms by SSCP and its effect on reproductive traits in Japanese flounder (Paralichthys olivaceus). Comp. Biochem. Physiol. Part B. 150:278-283.

He, F., H. S. Wen, J. F. Li., D. H. Yu, R. Q. Ma, D. Shi, W. J. Mu, Y. Q. Zhang, J. Hu, M. Liu, W. G. Han, J. N. Zhang, Q. Q. Wang, Y. R. Yuan and Q. Liu. 2011. Single nucleotide polymorphisms of the GnRHR gene associated with reproductive traits of Japanese flounder (Paralichthys olivaceus). Asian-Aust. J. Anim. Sci. 24:463-470.

Kazeto, Y., S. Ijiri, T. Todo, S. Adachi and K. Yamauchi. 2000. Molecular cloning and characterization of Japanese eel ovarian P450c17 (CYP17) cDNA. Gen. Comp. Endocrinol. 118:123133. 
Liao, P. Y. and K. H. Lee. 2010. From SNPs to functional polymorphism: The insight into biotechnology applications. Biochem. Eng. J. 49:149-158.

Liu, Z. J. and J. F. Cordes. 2004. DNA marker technologies and their applications in aquaculture genetics. Aquaculture 238:137.

Liu, Z. J. 2007. Single nucleotide polymorphism (SNP). In: Aquaculture Genome Technologies (Ed. Z. J. Liu). BPublishing Inc., USA.

Miyoshi, Y., A. Andoa, M. Ookaa, E. Shibab, T. Taguchi and Y. Tamaki. 2003. Association of CYP17 genetic polymorphism with intra-tumoral estradiol concentrations but not with CYP17 messenger RNA levels in breast cancer tissue. Cancer Lett. 195:81-86.

Nakajin, S., J. E. Shively, P. M. Yuan and P. F. Hall. 1981. Microsomal cytochrome P450 from neonatal pig testis: two enzymatic activities (17 $\alpha$-hydroxylase and C17, 20-lyase) associated with one protein. Biochemistry 20:4037-4042.

Orita, M., Y. Suzuki, T. Sekiya and K. Hayashi. 1989. Rapid and sensitive detection of point mutations and DNA polymorphisms using the polymerase chain reaction. Genomics 5:874-879.

Pawapol, K., P. Yniv, M. H. Eric, H. Gideon and D. Lior. 2010. SNP discovery and development of genetic markers for mapping innate immune response genes in common carp (Cyprinus carpio). Fish Shellfish Immunol. 29:356-361.

Payne, A. H. 1990. Hormonal regulation of cytochrome P450 enzymes, cholesterol side-chain cleavage and $17 \alpha$ hydroxylase $/ \mathrm{C}_{17-20}$ lyase in Leydig cells. Biol. Reprod. 42: 399-404.
Qu, L. J., X. Y. Li, G. Q. Wu and N. Yang. 2005. Efficient and sensitive method of DNA silver staining in polyacrylamide gels. Electrophoresis 26:99-101.

Rafalski, A. 2002. Applications of single nucleotide polymorphisms in crop genetics. Curr. Opin. Plant Biol. 5:94100

Sauna, Z. E., C. Kimchi-Sarfaty, S. V. Ambudkar and M. M. Gottesman. 2007. Silent polymorphisms speak: how they affect pharmacogenomics and the treatment of cancer. Cancer Res. 67:9609-9612.

Sirikan, P., K. Bavornlak, C. Parichat, K. Sirawut and M. Piamsak. 2010. Expression levels of RuvBL2 during ovarian development and association between its single nucleotide polymorphism (SNP) and growth of the giant tiger shrimp Penaeus monodon. Aquaculture 308:S83-S90.

Thanh, N. M., A. C. Barnes, P. B. Mather, Y. Li and R. E. Lyons. 2010. Single nucleotide polymorphisms in the actin and crustacean hyperglycemic hormone genes and their correlation with individual growth performance in giant freshwater prawn Macrobrachium rosenbergii. Aquaculture 301:7-15.

Weber, B. L. and K. L. Nathanson. 2000. Low penetrance genes associated with increased risk for breast cancer. Eur. J. Cancer 36:1193-1199.

Wei, B. B., Y. Y. Zhang, B. Xi, J. K. Chang, J. M. Bai and J. T. Su. 2010. CYP17 T27C polymorphism and prostate cancer risk: a meta-analysis based on 31 studies. J. Biomed. Res. 24:233-241.

Wen, H. S., H. X. Song, L. T. Yang, X. K. Mao and L. Gao. 2006. A study on the effects of exogenous hormone on the plasma testosterone and estradiol levels in cultured Japanese flounder. Acta. Ocean. Sin. 28:115-120 (in Chinese with English abstract). 